\title{
Rationale of Mesenchymal Stem Cell Therapy in Kidney Injury
}

\author{
Susanne V. Fleig ${ }^{a}$ d Benjamin D. Humphreys ${ }^{a-c}$ \\ a Renal Division, Brigham and Women's Hospital, and ${ }^{b}$ Harvard Medical School, Boston, Mass., and ${ }^{\mathrm{c} H a r v a r d ~ S t e m ~}$ \\ Cell Institute, Cambridge, Mass., USA; ${ }^{\mathrm{d}}$ Division of Nephrology, Hannover Medical School, Hannover, Germany
}

\section{Key Words}

Acute kidney injury · Kidney repair - Mesenchymal stem cells $\cdot$ Microvesicles $\cdot$ Renal tubules $\cdot$ Tissue repair

\begin{abstract}
Hundreds of clinical trials are currently investigating the potential for mesenchymal stem cells (MSC) to treat human disease, including kidney disease. There is tremendous excitement over the therapeutic potential of this form of stem cell therapy and an improving understanding of how MSC act. This review will summarize our current knowledge concerning the mechanisms by which MSC accelerate kidney repair after acute injury. It will also survey the current MSC clinical trial landscape in nephrology. Finally, future challenges to a widespread application of MSC therapies for patients with kidney injury will be outlined.

○ 2014 S. Karger AG, Basel
\end{abstract}

\section{Introduction}

Mesenchymal stem cells (MSC) are multipotent adult cells that have the ability to differentiate into cells of mesodermal origin, including chondroblasts, adipocytes and osteoblasts [1, 2]. MSC are best characterized in bone marrow, but it is now clear that they exist in many adult organs. In addition to their progenitor properties, MSC regulate tissue repair by interacting with resident cells and secreting soluble factors. These functions are broadly immunomodulatory, pro-repair, anti-apoptotic and proangiogenic.

\section{Mechanisms of MSC Protection against Acute Kidney Injury}

Numerous rodent studies have consistently documented a protective effect of MSC on both acute and chronic injury models. In a systematic meta-analysis of 21 of these studies [3], the authors found a consistent reduction in serum creatinine $(\mathrm{sCr})$ in MSC-treated animals versus controls. The studies differed in terms of time point and dose of MSC administered, time point of $\mathrm{sCr}$ measurement, route of MSC delivery, type of kidney injury and animal used (mice vs. rats). Subanalyses showed that the reduction in $\mathrm{sCr}$ in acute kidney injury (AKI)

Targeting Recovery from Acute Kidney Injury: Round Table Conference at the 19th International Conference on Continuous Renal Replacement Therapies (Manchester Grand Hyatt, San Diego, Calif., USA, March 2-3, 2014).

\section{KARGER}

E-Mail karger@karger.com www.karger.com/nec
(C) 2014 S. Karger AG, Basel

$1660-2110 / 14 / 1274-0075 \$ 39.50 / 0$
Dr. Benjamin D. Humphreys

Harvard Institutes of Medicine, Room 536

77 Avenue Louis Pasteur

Boston, MA 02115 (USA)

E-Mail bhumphreys@ partners.org 
models was highest in ischemia-reperfusion injury (mean, $43 \mu \mathrm{mol} / \mathrm{l}$ reduction) versus cisplatin- or glycerol-induced models $(29 \mu \mathrm{mol} / \mathrm{l})$, and all AKI models had a higher reduction than models of chronic kidney disease (5/6 nephrectomy, mean reduction $21 \mu \mathrm{mol} / \mathrm{l})$. In terms of dosage, high-dose ( $>10^{6}$ MSC) administration showed better results than low-dose $\left(<10^{6} \mathrm{MSC}\right)$ administration, and the reduction in $\mathrm{sCr}$ was higher if $\mathrm{MSC}$ were given at a later time point ( $>1$ day after injury) versus an earlier time point ( $<1$ day after injury). If sCr was measured in the first 3 days after injury and treatment, the reduction in $\mathrm{sCr}$ was more pronounced than when measured at a later time point, and intra-arterial injection of MSC (vs. intravenous or intrarenal application) had the best protective effect on kidney function.

Early studies proposed that the mechanism by which MSC repair renal tubules was through direct engraftment and differentiation into epithelial cells. However, subsequent lineage analysis documented conclusively that MSC do not differentiate into epithelia. Indeed, one study found that either intraperitoneal MSC injection or injection of the conditioned media from MSC cultures could replicate the protective effect of MSC in AKI [4]. Thus, it is now accepted that MSC act by secreting paracrine factors and interacting with cells within the kidney interstitium (fig. 1).

Much recent progress has been made in defining the factors that mediate paracrine repair by MSC. Analysis of MSC-conditioned media showed a high expression of more than 40 cytokines $[5,6]$, among which were granulocyte colony-stimulating factor, vascular endothelial growth factor, hepatocyte growth factor, interleukin (IL)10, epidermal growth factor and insulin-like growth factor (IGF)-1, which all have been shown to rescue mice from cisplatinum-induced kidney injury. Exciting recent discoveries have implicated MSC-derived microvesicles (MV) in the amelioration of AKI [7]; in vitro, cisplatininjured human tubular cells treated with MSC-MV expressed more anti-apoptotic genes such as Bcl-Xl (B-cell lymphoma-extra large), Bcl-2 (B-cell lymphoma 2 ) and Birc 8 (baculoviral IAP repeat containing 8 ), while proapoptotic genes such as caspase- 1 , caspase- 8 and LTA (lymphotoxin $\alpha$ ) were downregulated. MV and exosomes secreted from MSC not only contain cytokines, but also mRNA and microRNA, which are then taken up by host cells. Bruno et al. [8] did a gene array analysis on MSCMV and found 239 different mRNA transcripts, of which 132 could be identified (see tables 1 and 2 in [8]).

Gatti et al. [9] treated rats with MV isolated from human adult MSC after uninephrectomy and unilateral ischemia (45 min) and could show a protective effect of short- ( $48 \mathrm{~h}$ ) and long-term (6 months) MV treatment; in the short-term treated group, MV injection resulted in more tubular epithelial proliferation and less apoptosis, as well as lower levels of sCr, BUN and proteinuria. This effect was abrogated when the MV were treated with RNAse before injection.

It has long been known that IGF-1 secreted by MSC improved the viability of proximal tubular epithelial cells after cisplatin damage [10], and MSC silenced for IGF-1 lost their protective effect when injected into rodents after kidney damage; what was not known until recently is that MSC-MV also shuttle the mRNA for the IGF receptor (IGFR) [11]; MSC-secreted exosomes contain mRNA for IGFR as well as IGF-1. When treating IGFR-negative proximal tubular epithelial cells with MSC-conditioned media, these cells started to express IGFR and turned on IGF signaling.

Another interesting finding is that MSC-MV change their content depending on the environment in which they are cultured; Kilpinen et al. [12] compared MSCconditioned media in the presence or absence of interferon- $\gamma$ mimicking an inflammatory microenvironment. They compared the ability of MSC to protect rats from reperfusion injury in vivo; while the MSC cultured under normal conditions had a protective effect on kidney function, this effect was abrogated when the cells were cultured in the presence of interferon- $\gamma$. Proteome analysis of the different conditioned media showed that the protein content differed by $50-66 \%$.

\section{Harnessing the Beneficial Effects of MSC Clinically - Ongoing and Past Trials}

To date, there are 10 active clinical trials (phase 1/2) registered that involve intravascular application of MSC in acute or chronic kidney disease, autoimmune disease affecting the kidney or kidney transplantation (clinicaltrials.gov, summarized in table 1). The first trials to report results are those in kidney transplantation. In a pilot study in 2 patients, autologous bone marrow-derived MSC were infused intravenously for 7 days after livingrelated donor kidney transplantation [13]; 3 patients with the same immunosuppressive therapy and living donor kidney transplantation served as a control group. The authors found a temporary decrease in graft function following MSC in both patients, leading them to conclude that the protocol should be changed to MSC infusion before transplant. All patients were followed up for 1 year;
Fleig/Humphreys 


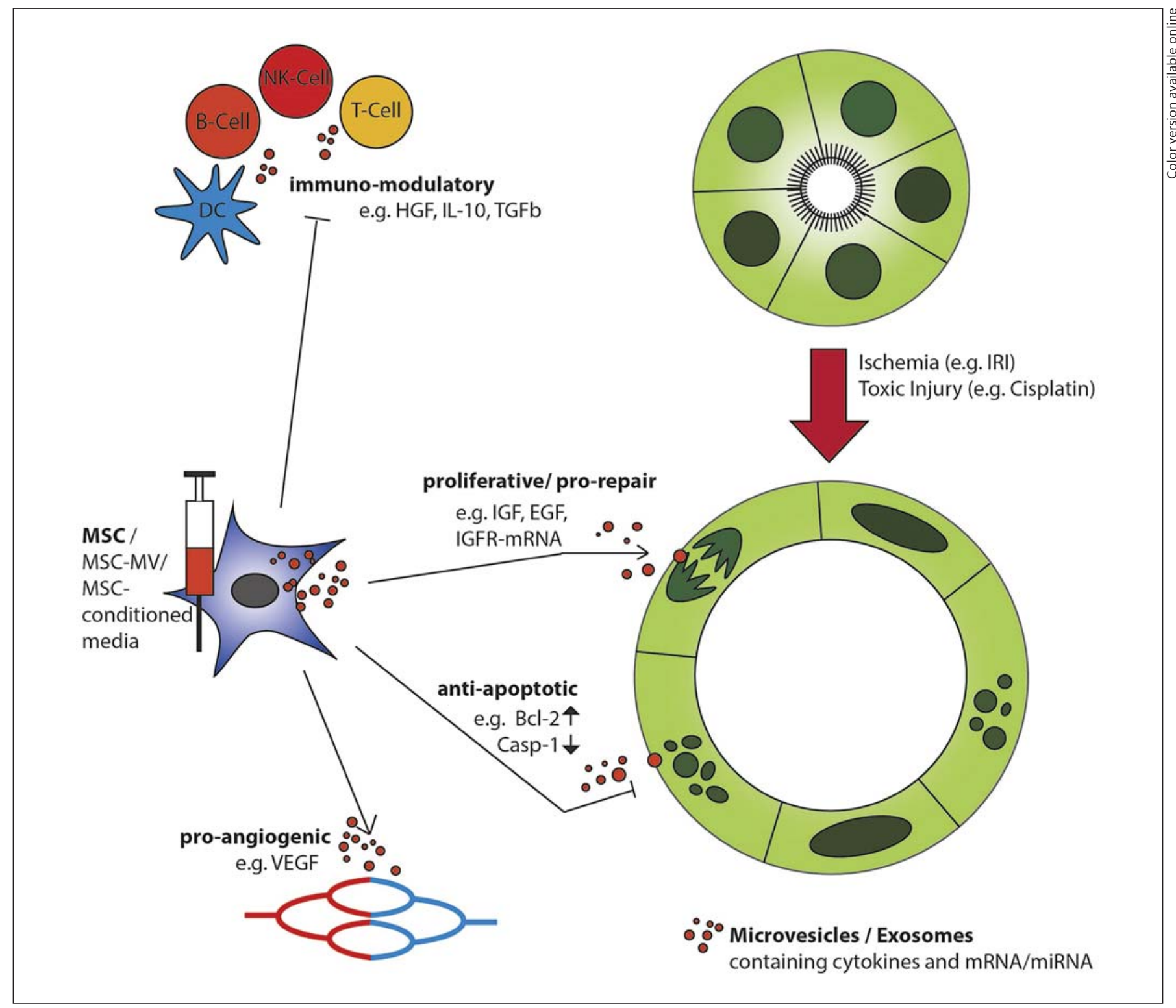

Fig. 1. Model for paracrine actions of MSC on the injured tubule and surrounding tissue. Injections of MSC, MSC-MV or MSCconditioned media accelerate repair by supporting proliferation and inhibiting apoptosis of tubular cells, induce vascular growth and inhibit inflammation/modulate immune responses, e.g. in
AKI patients after kidney transplantation. The secreted MV contain both cytokines and mRNA/microRNA (miRNA). HGF $=\mathrm{He}$ patocyte growth factor; TGFb = transforming growth factor $\beta$; EGF = epidermal growth factor; IRI = ischemia-reperfusion injury; Casp -1 = caspase 1 ; VEGF $=$ vascular endothelial growth factor. at this time point, all patients had a comparable kidney function, yet the 2 MSC-treated patients had a decreased population of memory CD8+ T cells within the CD8+ Tcell population in the peripheral blood, which was also associated with reduced CD8+ T-cell activity. The authors concluded that MSC infusion in kidney transplant recipients restricts memory $\mathrm{T}$-cell expansion, although with a study group consisting of 2 patients, this is rather anecdotal evidence.

In a second pilot study with again 2 patients in the experimental group [14], MSC infusion before transplant did not lead to acute graft dysfunction in 1 patient; a basiliximab-free induction therapy did not lead to expansion of the CD4+FoxP3+ regulatory $\mathrm{T}$-cell pool; for the next 
Table 1. Ongoing/completed clinical trials registered at clinicaltrials.gov (as of February 2014) involving intravascular MSC application and kidney disease or function among the endpoints

\begin{tabular}{|c|c|c|c|c|c|c|}
\hline $\begin{array}{l}\text { Topic/ } \\
\text { NCT No. }\end{array}$ & Title & Conditions & Kidney-related outcome measures & $\begin{array}{l}\text { Recruit- } \\
\text { ment }\end{array}$ & $\begin{array}{l}\text { Enroll- } \\
\text { ment } \\
\text { (planned) }\end{array}$ & $\begin{array}{l}\text { Comple- } \\
\text { tion date } \\
\text { (planned) }\end{array}$ \\
\hline NCT01275612 & $\begin{array}{l}\text { MSC in cisplatin-induced acute } \\
\text { renal failure in patients with solid } \\
\text { organ cancers }\end{array}$ & $\begin{array}{l}\text { Cisplatin-induced } \\
\text { AKI }\end{array}$ & sCr, NGAL, NAG & Recruiting & 9 & $\begin{array}{l}\text { March } \\
2014\end{array}$ \\
\hline \multicolumn{7}{|c|}{ Autoimmune diseases } \\
\hline NCT01539902 & $\begin{array}{l}\text { Phase } 2 \text { study of human umbilical } \\
\text { cord-derived MSC for the } \\
\text { treatment of lupus nephritis }\end{array}$ & Lupus nephritis & Efficacy and safety & Recruiting & 25 & $\begin{array}{l}\text { May } \\
2013\end{array}$ \\
\hline NCT01741857 & $\begin{array}{l}\text { Umbilical cord-derived MSC trans- } \\
\text { plantation for active and refractory } \\
\text { systemic lupus erythematosus }\end{array}$ & $\begin{array}{l}\text { Systemic lupus } \\
\text { erythematosus }\end{array}$ & $\begin{array}{l}\text { Renal function (GFR, BUN, } \\
\text { urinalysis), BILAG score, lupus } \\
\text { serology }\end{array}$ & Recruiting & 40 & $\begin{array}{l}\text { December } \\
2013\end{array}$ \\
\hline NCT01876017 & $\begin{array}{l}\text { Safety and efficacy of MSC in } \\
\text { patients with chronic renal failure }\end{array}$ & $\begin{array}{l}\text { Chronic renal } \\
\text { failure }\end{array}$ & $\begin{array}{l}\text { Incidence of uremia and dialysis } \\
\text { requirement; serum urea and sCr }\end{array}$ & $\begin{array}{l}\text { Not yet } \\
\text { recruiting }\end{array}$ & 15 & $\begin{array}{l}\text { December } \\
2014\end{array}$ \\
\hline \multicolumn{7}{|c|}{ Kidney transplantation } \\
\hline NCT01429038 & $\begin{array}{l}\text { MSC after renal or liver } \\
\text { transplantation }\end{array}$ & $\begin{array}{l}\text { Kidney failure after } \\
\text { transplantation }\end{array}$ & $\begin{array}{l}\text { Biopsy-proven (Banff) rejection } \\
\text { rates, graft function, feasibility and } \\
\text { safety of weaning immunosuppres- } \\
\text { sion, immune function, anti-MSC } \\
\text { donor HLA antibodies }\end{array}$ & Recruiting & 40 & $\begin{array}{l}\text { February } \\
2017\end{array}$ \\
\hline NCT00752479 & $\begin{array}{l}\text { MSC under basiliximab/low-dose } \\
\text { RATG to induce renal transplant } \\
\text { tolerance }\end{array}$ & Kidney transplant & $\begin{array}{l}\text { Graft function, graft rejection; } \\
\text { T-cell response/anergy, peripheral } \\
\text { blood; regulatory T cells }\end{array}$ & Terminated & 4 & $\begin{array}{l}\text { December } \\
2013\end{array}$ \\
\hline
\end{tabular}

study, the protocol will again be altered to include basiliximab to prevent patients from the risk of an early rejection. Overall, kidney function was again as good as in the MSC-free control patients after 1 year, and no other adverse effects of MSC injection were reported.

In a safety and feasibility study (phase 1 [15]), patients with acute allograft rejection at control biopsies (4 weeks or 6 months after kidney transplantation) received intravenous injections of autologous bone marrow-derived MSC and were followed up for 24 weeks $(n=6)$. Infusions were tolerated without adverse effects; follow-up biopsies in 2 patients showed resolution of tubulitis, and 5 of 6 pa- tients had less donor-specific peripheral mononuclear cells, pointing towards a possible immune-modulatory effect of the treatment.

The largest published study to date enrolled 159 patients undergoing living donor-related kidney transplantation (NCT00658073 [16]). The two groups receiving autologous bone marrow-derived MSC at the time point of reperfusion and 2 weeks after kidney transplantation differed by having a standard or low dose ( $80 \%$ of standard) of calcineurin inhibitor treatment; the control group did not receive MSC, but an anti-IL-2 receptor antibody and a standard dose of calcineurin inhibitor. After 
1 year, the incidence of biopsy-confirmed acute rejection was 7.5 and $7.7 \%$, respectively, in the two MSC-treated groups, whereas it was $21.6 \%$ in the control group receiving IL-2 receptor antibody and a standard dose of calcineurin inhibitor. Also, kidney function at 1 year was better in the MSC-treated groups, and the patients in these groups had less opportunistic infections. The rate of adverse effects was lower in the MSC-treated group than in the control group within the 360-day follow-up period.

In the field of AKI, a phase 1 study has been finished in which 16 cardiac surgery patients at high risk for postoperative AKI were safely treated with allogeneic MSC (NCT00733876 [17]) injected into the suprarenal aorta. During a 6-month follow-up period, no adverse effects of treatment were reported, and MSC-treated patients seemed to have less kidney injury and a shorter hospital stay. Currently, a larger trial is underway including 200 patients undergoing coronary artery bypass grafting (NCT01602328, www.allocure.com/clinical/index.php); enrollment is likely to close in December 2014, and results are to be expected in January 2016.

Overall, intravenous injection of autologous MSC seems to be safe within the 1st year after treatment, yet long-term results and a longer follow-up than 1 year are needed to judge whether this holds true on the long run. Unfortunately, there are no results published yet from studies involving MSC treatment in autoimmune kidney disease or chronic renal failure.

\section{Future Challenges to Human Application of MSC in Kidney Injury}

Despite the number of ongoing MSC-based human clinical trials, long-term safety concerns remain based upon results from animal studies. Breitbach et al. [18] injected green fluorescent protein (GFP)-labeled mouse bone marrow-derived MSC into the heart in myocardial infarction mouse models and traced them over 132 days; they did not find any GFP-positive cardiomyocytes or GFP-positive vascular smooth muscle cells, which argues against transdifferentiation of MSC into these cell types. Instead, they found GFP-positive cells and amorphous material in encapsulated structures in the scars, and these structures contained calcifications, which were verified by von Kossa staining, suggesting maldifferentiation of injected MSC into bone tissue.

In a different study using a rat model of glomerulonephritis, the authors reported a short-term improvement in kidney function after MSC injection on day 10 [19] - yet, at 2 months, they found intraglomerular adipocytes that had transdifferentiated from MSC, leading to glomerulosclerosis. Also, while early investigations reported homing of MSC to injured tissue, more recent studies predominantly show that the majority of injected MSC (67.2\%) embolize in the lung [5] and only a small fraction (5.4\%) is found in the kidney $1 \mathrm{~h}$ and 1 day after injection: after 7 days, MSC were undetectable in the lung or kidneys - they did not engraft.

Given the strong data emphasizing a paracrine mechanism of action of MSC, clearly more work is needed to identify the soluble factors secreted by MSC that mediate repair, since these may be therapeutic alone. Yet MSC show great promise, and most concerns regarding their long-term safety are theoretical at this point. Indeed, one reason for the number of MSC clinical trials existent is their excellent safety profile to date.

\section{Conclusion}

The area of MSC therapy for kidney injury is very promising with - so far - good safety profiles in clinical studies, even with the relatively crude method of injecting whole cells intravenously. MSC have the advantage of relatively easy isolation and culture conditions, making them a potentially low-cost and personalized therapy option for patients with kidney injury. Still, adverse effects of treatment with MSC are possible and have been described in animal studies, and most data suggest that engraftment of the cells into the diseased organs is transient.

Despite the absence of long-term safety data, MSC therapy for kidney injury is one of the most exciting areas involving new therapeutics and the results of current clinical trials for kidney indications are sure to better define the potential of these cells to treat human disease.

\footnotetext{
References $\quad 1$ Humphreys BD, Bonventre JV: Mesenchymal stem cells in acute kidney injury. Annu Rev Med 2008;59:311-325.

2 Bianco P, et al: The meaning, the sense and the significance: translating the science of mesenchymal stem cells into medicine. Nat Med 2013;19:35-42.

3 Wang Y, et al: Systematic review and metaanalysis of mesenchymal stem/stromal cells therapy for impaired renal function in small animal models. Nephrology (Carlton) 2013; 18:201-208.

4 Bi B, et al: Stromal cells protect against acute tubular injury via an endocrine effect. J Am Soc Nephrol 2007;18:2486-2496.
}

Rationale of MSC Therapy in Kidney Injury
Nephron Clin Pract 2014;127:75-80 DOI: $10.1159 / 000363680$ 
5 Cheng K, et al: Transplantation of bone marrow-derived MSCs improves cisplatinum-induced renal injury through paracrine mechanisms. Exp Mol Pathol 2013;94:466-473.

$\checkmark 6$ Chen L, et al: Paracrine factors of mesenchymal stem cells recruit macrophages and endothelial lineage cells and enhance wound healing. PLoS One 2008;3:e1886.

7 Bruno S, et al: Microvesicles derived from mesenchymal stem cells enhance survival in a lethal model of acute kidney injury. PLoS One 2012;7:e33115.

-8 Bruno S, et al: Mesenchymal stem cell-derived microvesicles protect against acute tubular injury. J Am Soc Nephrol 2009;20:1053-1067.

$\checkmark 9$ Gatti S, et al: Microvesicles derived from human adult mesenchymal stem cells protect against ischaemia-reperfusion-induced acute and chronic kidney injury. Nephrol Dial Transplant 2011;26:1474-1483.
10 Imberti B, et al: Insulin-like growth factor-1 sustains stem cell mediated renal repair. J Am Soc Nephrol 2007;18:2921-2928.

11 Tomasoni S, et al: Transfer of growth factor receptor mRNA via exosomes unravels the regenerative effect of mesenchymal stem cells. Stem Cells Dev 2013;22:772-780.

12 Kilpinen L, et al: Extracellular membrane vesicles from umbilical cord blood-derived MSC protect against ischemic acute kidney injury, a feature that is lost after inflammatory conditioning. J Extracell Vesicles 2013;2, DOI: 10.3402/jev.v2i0.21927.

13 Perico N, et al: Autologous mesenchymal stromal cells and kidney transplantation: a pilot study of safety and clinical feasibility. Clin J Am Soc Nephrol 2011;6:412-422.

14 Perico N, et al: Mesenchymal stromal cells and kidney transplantation: pretransplant infusion protects from graft dysfunction while fostering immunoregulation. Transpl Int 2013;26:867-878.
15 Reinders ME, et al: Autologous bone marrowderived mesenchymal stromal cells for the treatment of allograft rejection after renal transplantation: results of a phase I study. Stem Cells Transl Med 2013;2:107-111.

16 Tan J, et al: Induction therapy with autologous mesenchymal stem cells in living-related kidney transplants: a randomized controlled trial. JAMA 2012;307:1169-1177.

17 Togel FE, Westenfelder C: Kidney protection and regeneration following acute injury: progress through stem cell therapy. Am J Kidney Dis 2012;60:1012-1022.

18 Breitbach $\mathrm{M}$, et al: Potential risks of bone marrow cell transplantation into infarcted hearts. Blood 2007;110:1362-1369.

19 Kunter U, et al: Mesenchymal stem cells prevent progressive experimental renal failure but maldifferentiate into glomerular adipocytes. J Am Soc Nephrol 2007;18:1754-1764. 